\title{
A CONSERVATIVIDADE DA DENOTAÇÃO DOS DETERMINANTES
}

\author{
Luiz Arthur Pagani *
}

\section{Introdução}

\section{A} presenta-se aqui um resumo do segundo capítulo do manual de semântica de Chierchia (1997), no qual se discute a denotação dos determinantes, que é sempre uma relação conservativa, pelo que se tem notícia, em todas as línguas.

As palavras funcionais sempre foram um obstáculo à semântica, na qual as expressões denotam objetos: que tipo de objeto denotará uma preposição ou um artigo? A princípio, elas não parecem denotar nada, ainda que apresentem uma contribuição semântica importante. Como é possível conciliar essa contribuição com o conceito de denotação, tão importante para a semântica?

Exemplificaremos essa questão através dos chamados determinantes ${ }^{1}$ que são expressões que, no português, precedem os nomes nos seguintes exemplos:

* Universidade Estadual de Londrina

1 Na gramática gerativa, em geral, os elementos como um, todo e nenhum são tratados como quantificadores; mas isso não afeta a questão desenvolvida aqui. O importante é que ambos podem ser genericamente definidos como especificador do sintagma nominal. 

a. Um homem fuma.
b. Todo homem fuma.
c. Mais do que três homens fumam.

Os determinantes incluem, portanto, os artigos (o, $a$, um e uma) e outros elementos que exprimem quantos objetos de uma certa classe devem ser considerados (como todo e mais do que três). Alguns determinantes são constituídos por uma única palavra; outros, como mais do que três, são sintagmas.

\section{Semântica denotacional e teoria de conjunto}

A idéia central da semântica denotacional é que as sentenças declarativas estão associadas a condições de verdade que dependem da referência das expressões que as compõem e do modo pelo qual tais expressões são combinadas. Assim, por exemplo, Pedro dorme seria verdadeira numa situação $t$ (o momento em que é pronunciada) apenas quando o indivíduo denotado por Pedro pertencer à classe dos indivíduos que, na situação $t$, dormem. Observe que na formulação dessas condições foi usado o conceito de classe ou conjunto. Quem não está familiarizado com a teoria dos conjuntos pode estranhar essa concepção, na qual cada aspecto da realidade é concebido como um conjunto de algum tipo. Mas, os conjuntos são uma espécie de óculos pelos quais o semanticista vê o mundo. Graças à sua estrutura matemática, simples e precisa, eles nos farão perceber algumas regularidades que, de outra forma, não veríamos. A teoria dos conjuntos é como um microscópio ou um telescópio para a semântica: é o instrumento que serve para perceber aquém e além de nossa percepção normal.

\section{Uma gramática-modelo}

Uma semântica denotacional exige primeiro a determinação do modo pelo qual as expressões são combinadas; depois, é necessário especificar as denotações das expressões básicas e determinar como elas são combinadas para resultar na denotação das expressões mais complexas. A gramática $\mathrm{G}_{1}$, a seguir vai servir como modelo rudimentar inicial desse funcionamento das línguas naturais. 
(2) Sintaxe de $G_{1}$

a. Léxico

- os nomes (N) são: Pedro, Paulo, ...

- os verbos intransitivos $\left(\mathrm{V}_{\mathrm{i}}\right)$ são: dorme, sua, ...

- os verbos transitivos $\left(\mathrm{V}_{\mathrm{t}}\right)$ são: ama, olha para, ...

b. Regras sintáticas

As sentenças bem formadas são cadeias de elementos da seguinte forma:

$-\mathrm{N} \mathrm{Vi}$

$-\mathrm{N} \mathrm{V}_{\mathrm{t}} \mathrm{N}$

(3) Semântica de $G_{1}$

Para toda possível circunstância de enunciação $t$,

a. os membros de $\mathrm{N}$ denotam indivíduos: Pedro denota em $t$ o indivíduo reconhecido com o Pedro, etc.;

b. os membros de $\mathrm{V}_{\mathrm{i}}$ denotam classes de indivíduos: dorme denota em $t$ o conjunto dos que dormem ( $\{x: x$ dorme em $t\})$, sua denota em $t$ o conjunto dos que suam $(\{x: x$ sua em $t\})$, etc.;

c. os membros de $\mathrm{V}_{\mathrm{t}}$ denotam relações entre indivíduos: ama denota em $t$ a relação $\{\langle x, y\rangle: x$ ama $y$ em $t\}$, olha para denota em $t$ a relação $\{\langle x, y\rangle: x$ olha para $y$ em $t\}$, etc.;

d. uma sentença com a forma " $\mathrm{N} \mathrm{V}$ " é verdadeira em $t$ apenas quando $u \in A$, onde $u$ é o indivíduo denotado por $\mathrm{N}$ em $t$ e $A$ é a classe denotada por $\mathrm{V}_{\mathrm{i}}$ em $t$;

e. uma sentença com a forma " $\mathrm{N} \mathrm{V}_{\mathrm{t}} \mathrm{N}$ " é verdadeira em $t$ apenas quando $\left[u, u^{\prime}\right] \in R$, onde $u$ é o indivíduo denotado pelo primeiro $\mathrm{N}$ em $t$, $u$ 'é o indivíduo denotado pelo segundo $\mathrm{N}$ em $t$ e $R$ é a relação denotada por $\mathrm{V}_{\mathrm{t}}$ em $t$.

Esta gramática gera sentenças do português com a forma sujeito-verbo e sujeito-verbo-objeto. Acrescentando outras entradas lexicais (isto é, outras 
palavras), as sentenças geradas por essa gramática aumentaria cada vez mais.

\section{A semântica dos determinantes}

A semântica denotacional exige que achemos uma denotação para os determinantes, a fim de especificarmos depois as condições de verdade das sentenças nas quais eles ocorram. Mas, não parece claro que tipo de coisa essa denotação possa ser. No modelo apresentado em (2) e (3), a questão se coloca nos seguintes termos: o que é preciso fazer para acrescentar à gramática $G_{1}$ sentenças com determinantes? Restringindo-nos apenas ao sujeito, as regras sintáticas a serem incluídas em (2) são fáceis de formular:

(4) a. os nomes comuns $\left(\mathrm{N}_{\mathrm{c}}\right)$ são: homem/homens, casa/casas, etc.

b. os determinantes (Det) são: todo, um, mais do que três, etc.

c. uma cadeia com a forma "Det $\mathrm{N}_{\mathrm{c}} \mathrm{V}_{\mathrm{i}}$ " é uma sentença bem formada (caso Det e $\mathrm{N}_{\mathrm{c}}$ concordem em gênero e número). ${ }^{2}$

A parte semântica exige a inclusão em (3) de regras com a forma:

a. Os membros de $\mathrm{N}_{\mathrm{c}}$ denotam classes de indivíduos: homem / homens denota na circunstância $t$ o conjunto $\{x: x$ é um homem em $t\}$, casa/casas denota na circunstância $t$ o conjunto $\{x /$ é uma casa em $t\}$

A regra em (5a) é bastante evidente. Parece plausível que um nome comum no singular denote uma classe de indivíduos. Talvez seja menos evidente que um nome comum no plural tenha essa mesma denotação. No entanto, adotaremos aqui essa hipótese por simplicidade. Nosso problema é como incluir em (5) as regras que dão conta dos determinantes e das sentenças nas quais eles ocorram.

Nossa abordagem sugere uma solução. Considere um exemplo como (6):

$$
\begin{array}{lcc}
\text { Det } & \mathrm{N}_{\mathrm{c}} & \mathrm{V}_{\mathrm{i}} \\
\text { todo } & \text { homem } & \text { fuma }
\end{array}
$$

2 Obviamente, os determinantes e os nomes precisam concordar: uma casa e não *um casa, muitas crianças e não *muita crianças, etc. Mas, não nos ocuparemos dessa questão aqui. 
Sabemos que homem denota a classe dos homens e fuma a classe dos indivíduos que fumam. Sabemos ainda que, combinando homem e fuma com todo temos uma sentença. Qual é então a contribuição de todo? Evidentemente, algo que relacione a classe dos homens com a dos fumantes. Em particular, todo exprime a relação de 'ser um subconjunto de': todo homem fuma é verdadeira (em $t$ ) apenas quando o conjunto dos homens for um subconjunto das pessoas que fumam. Então, empregando a notação introduzida em (3), o que a sentença (6) diz poderia ser expresso assim:
a. $\{x: x$ é um homem em $t\} \subseteq\{x: x$ fuma em $t\}$
b.

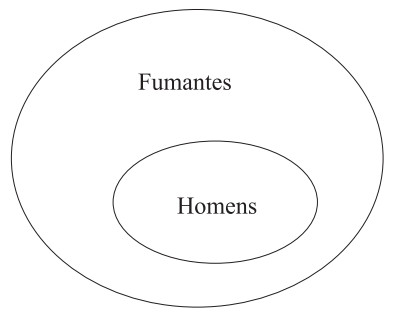

Assim, a diferença entre (7a) e (6) reside apenas no fato de que, no português, o sinal que exprime a relação 'ser um subconjunto de' ocorre no início da sentença, antes dos relata (as entidades relacionadas), enquanto que na notação conjuntística ele ocorre entre os relata.

Podemos assim concluir que todo denota a relação Í. Uma sentença do português com a forma " todo $N V$ ” é verdadeira quando a classe denotada pelo $\mathrm{N}$ for um subconjunto da classe denotada pelo V. De forma esquematizada:

$$
\begin{array}{ccc}
\text { Todo } & \text { homem } & \text { fuma } \\
\text { é um subconjunto de } & \{x: x \text { é homem em } t\} & \{x: x \text { fuma em } t\}
\end{array}
$$

Ainda que seja bastante óbvio, é interessante observar que o determinante plural todos, em sentenças como Todos os homens fumam, parece apresentar essencialmente a mesma semântica de todo. ${ }^{3}$ Uma sentença como essa é verdadeira apenas quando o conjunto dos homens for um subconjunto do conjunto dos fumantes. Portanto, todos também (ou melhor, o sintagma todos os)

3 Essa é uma simplificação. Todos, por exemplo, nos permite falar de um conjunto como entidade coletiva, enquanto todo tende a referir-se distributivamente a membros individuais de um conjunto. Compare, por exemplo: (a) Todos os rapazes estão reunidos no pátio e (b) *Todo rapaz está reunido no pátio. Essa questão, no entanto, não será aprofundada aqui. 
será interpretado como a relação de 'ser um subconjunto de', o que justifica a nossa suposição de que (ao menos em relação a certos fenômenos) a diferença entre plural e singular seja fundamentalmente de natureza morfossintática.

Se essa hipótese sobre o significado de todo e todos estiver correta, é de se esperar que outros determinantes também exprimam relações entre conjuntos, já que os membros de uma categoria sintática apresentam denotações do mesmo tipo: os nomes comuns denotam classes de objetos, os verbos transitivos denotam relações entre objetos, e assim por diante. Pode-se, portanto, imaginar que a análise de todo, segundo a qual os determinantes denotam relações entre conjuntos, se alastre a todos os determinantes.

Considere-se o determinante um, em sentenças do tipo um homem fuma ${ }^{4}$ Que tipo de relação entre conjuntos poderia corresponder ao determinante um? Para que um homem fuma seja verdadeira, deve haver pelo menos um membro do conjunto dos homens que também seja membro do conjunto dos fumantes; o que é preciso fazer, portanto, é observar o que há na intersecção entre o conjunto $H$ dos homens e o conjunto $F$ dos fumantes (ou seja, $H \cap F$ ). Para que um homem fuma seja verdadeira, esta intersecção deverá conter pelo menos um elemento; ou seja, $H \cap F \neq \varnothing$. Conseqüentemente, um exprime a relação que $H$ contrai com $F$ apenas quando a intersecção de $H \operatorname{com} F$ não for vazia. De forma esquemática:

a. $u m$

homem

fuma

há uma intersecção

não vazia de $\{x: x$ é homem em $t\} \quad\{x: x$ fuma em $t\}$

b. se os conjuntos $H$ e $F$ estiverem como abaixo, um homem fuma é verdadeira

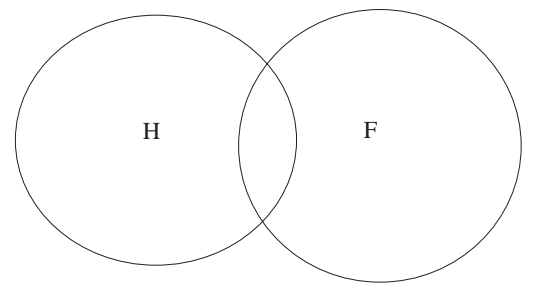

4 A sentença um homem fuma tem duas leituras: uma genérica (exemplificada por sentenças como efetivamente, um homem fuma; mas uma mulher não) e uma não-genérica (exemplificada por olha, naquele grupo um homem fuma). Aqui, a leitura genérica será desconsiderada. 
c. se os conjuntos $H$ e $F$ estiverem como abaixo, um homem fuma é falsa
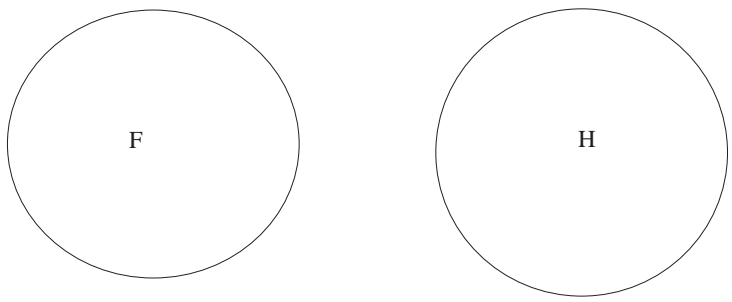

Um outro caso interessante é o do determinante nenhum, que constitui a negação de um. Considere-se uma sentença como nenhum homem fuma. Sob que condições essa sentença é verdadeira? De um ponto de vista intuitivo, ela trata de situações nas quais nenhum membro do conjunto $H$ dos homens seja também membro do conjunto $F$ dos fumantes. Em outros termos, a intersecção $H \cap F$, entre homens e fumantes, deve ser vazia. Conseqüentemente, o determinante nenhum também exprime uma relação entre conjuntos, a relação que $H$ e $F$ contraem quando a sua intersecção for vazia (ou seja, quando $H \cap F$ $=\varnothing)$. Isto é o oposto da relação expressa por um.

Apesar de ainda haver muitos determinantes a serem considerados, a hipótese de que as expressões dessa classe estejam semanticamente associadas a relações entre conjuntos, parece efetivamente corroborada pelos casos particulares que consideramos.

Agora estamos aptos a completar a semântica de (5) e, portanto, a interpretar sentenças da forma "Det $N V$ ' em geral:

(10) a. Os membros de Det denotam relações entre conjuntos: todo denota a relação 'ser subconjunto de', um denota a relação 'ter uma intersecção não-vazia’, etc.

b. Uma sentença com a forma "Det $N_{c} V_{i}$ " é verdadeira em $t$ apenas quando os conjuntos denotados por $N_{c}$ e $V_{i}$ estejam efetivamente relacionados entre si em $t$ através da relação $R$ associada a Det.

A gramática $\mathrm{G}_{1}$, incrementada por essas, regras, fornece uma caracterização da sintaxe de algumas sentenças simples do português, nas quais figuram os determinantes (na posição de sujeito), e de sua semântica. Ela oferece ainda uma demonstração concreta de como a abordagem denotacional funciona. 


\section{Relações "conservativas"}

É preciso introduzir agora uma propriedade das relações entre conjuntos que não têm uma interpretação intuitiva imediata. Ela é uma propriedade matemática simples semelhante à simetria, mas se estabelece tanto entre conjuntos quanto entre indivíduos. A razão para introduzi-la é a de que se descobriu que todos os determinantes de todas as línguas apresentam essa propriedade. Este fato é surpreendente considerando que a priori não há nenhuma razão para isso.

A propriedade em questão é chamada de conservatividade e é definida assim:

(11) Se $A$ está na relação $R \operatorname{com} B$, então $A$ também está na relação $R$ $\operatorname{com} A \cap B$ e vice-versa.

Dizemos que $R$ é conservativa quando satisfaz a condição em (11). Um exemplo simples de relação conservativa é a relação 'ser um subconjunto de' (ou seja, Í). Se um conjunto $A$ é um subconjunto de $B$, temos a seguinte situação:

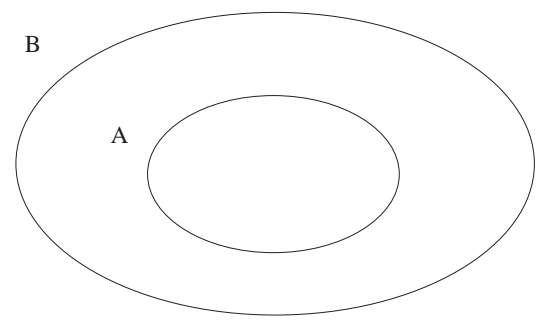

Nessa situação, $A$ também é um subconjunto de $A \cap B$, dado que a intersecção de $A$ e $B$ é o próprio $A$; e, por definição, todo conjunto é subconjunto de si mesmo. Inversamente, se assumimos que $A$ seja um subconjunto de $A \cap$ $B$, todos os membros de $A$ devem, por definição, estar tanto em $A$ quanto em $B$; mas isso significa que $A$ deve ser um subconjunto não só de si mesmo (o que é óbvio), mas de $B$ também. Portanto 'ser um subconjunto de' é uma relação conservativa porque vale o seguinte:

(13) $A \cap B$ é verdadeira apenas quando $A \subseteq(A \cap B)$ 
Um exemplo simples de relação não-conservativa é 'ser igual a' (denotada por $=$ ). Pode ser que $A$ seja idêntico à intersecção entre $A$ e $B$, sem ser idêntico a $B$. O diagrama (12), na página anterior, ilustra essa situação, na qual a parte direita da equação em (14) vale, mas a parte esquerda não. Portanto, a identidade não é conservativa porque não vale o seguinte:

$$
\text { (14) } A=B \text { é verdadeira apenas quando } A=(A \cap B)
$$

Esses exemplos mostram que existem relações que são conservativas e outras que não o são. Como então uma relação abstrata como a conservatividade pode se manifestar nas línguas naturais? Dissemos que os determinantes exprimem relações entre conjuntos, nas quais o primeiro relatum corresponde ao nome comum, enquanto o segundo corresponde ao verbo:

$\begin{array}{ccc}\text { Det } & \mathrm{N} & \mathrm{V} \\ \text { todo } & \text { homem } & \text { fuma } \\ \subseteq & A & B\end{array}$

Uma relação $R$ é conservativa apenas quando, toda vez que $R$ for verdadeira para $A$ e $B, R$ também for verdadeira para $A$ e $A \cap B$. Acabamos de ver que a relação 'ser um subconjunto de', associada a todo, é conservativa. Para compreender o que isso significa em relação à contraparte em português de $\subseteq$, devemos observar como se exprime em português a intersecção entre as denotações do nome e do verbo. Uma forma simples de exprimir isso é através de sentenças relativas: considere o predicado nominal ser um homem que fuma. A que classe de indivíduos se refere ser um homem que fuma? Evidentemente, a todos aqueles que são tanto homens quanto fumantes. Portanto, esse predicado denotará precisamente a intersecção do conjunto dos homens com o conjunto dos fumantes:

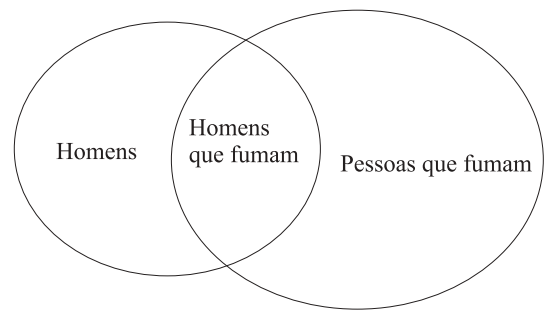


Nesse ponto, pode-se constatar se um determinante é conservativo observando se a seguinte equação vale:

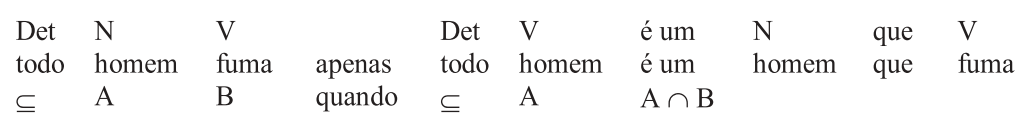

Imagine uma situação na qual todo homem seja um homem que fuma. Nessa situação seria verdade que todo homem fuma? Evidentemente que sim. Tente, então, imaginar que tenhamos uma situação na qual todo homem fume. Valerá nessa situação que todo homem é um homem que fuma? A resposta só pode ser afirmativa. Todo homem fuma e todo homem é um homem que fuma parecem ter o mesmo conteúdo: não há uma situação na qual uma possa ser verdadeira sem que a outra também o seja. Portanto, observando nossas intuições de falantes fomos capazes de dizer que para todo a equivalência em (17) vale. Isso confirma, empiricamente, que todo exprime uma relação conservativa, já que satisfaz a condição em (11). Assim, dispomos de um teste empírico que nos permite constatar se um determinante é conservativo sem precisar recorrer a raciocínios complicados. Tudo o que é preciso fazer é observar se uma expressão com a forma "Det $N V$ ' diz a mesma coisa que sua contraparte com a forma “ Det $N$ é um $N$ que $V$ '. Em caso afirmativo, o determinante é conservativo. Devemos aplicar a outros determinantes o teste que acabamos de aplicar a todo. Eis alguns casos relevantes:

(18) a. Um homem fuma.

a'. Um homem é um homem que fuma.

b. Nenhum homem fuma.

b'. Nenhum homem é um homem que fuma.

c. Três homens fumam.

c'. Três homens são homens que fumam.

d. A maior parte dos homens fumam.

d'. A maior parte dos homens são homens que fumam.

Os pares em (18) são efetivamente equivalentes (são, portanto, verdadeiras nas mesmas situações). Se for verdade, por exemplo, que nenhum homem fuma, também precisa ser verdade que nenhum homem é um homem que fuma, e vice-versa. Os outros exemplos também passam nesse mesmo teste. A partir desses dados, podemos concluir que os determinantes em português exprimem relações conservativas. Essa constatação também é corroborada pelo 
fato de não existir nenhum determinante para exprimir uma relação nãoconservativa como 'ser igual a'; ou seja, não há nenhuma sentença do português com a forma "D homens fumam" que queira dizer "os homens coincidem com os fumantes'. Mas isso não significa que a identidade não possa ser expressa em português. Quer dizer apenas que essa relação não pode ser expressa através de um Det. Essa limitação de Det, se confirmada por outros dados, constituiria uma descoberta surpreendente: seria como descobrir que todos os verbos transitivos exprimissem relações simétricas.

Mas, para não tirarmos conclusões apressadas, é preciso cautela. Pode ser que, se observarmos mais detalhadamente, encontremos algum determinante não conservativo. Considere, por exemplo, o seguinte par de sentenças:

(19) a. Apenas os homens fumam.

b. Apenas os homens são homens que fumam.

A expressão apenas os ocupa nas sentenças acima a posição canônica dos determinantes e parece ser completamente análoga ao sintagma todos os, analisado anteriormente como um determinante sinônimo de todo. Suponhamos, então, que essas sentenças digam a mesma coisa, que são verdadeiras nas mesmas condições. A sentença em (19a) diz que não existem fumantes que não sejam homens. Em outros termos, pode ser que ninguém fume, mas se alguém fuma, então esse alguém tem que ser um homem. Claramente, se houvesse um não-homem (por exemplo, um mico) que fuma, a sentença em (19a) seria falsa. Esse exame das condições de verdade de (19a) sugere que a relação expressa por apenas os é a relação de 'ser um superconjunto de', ou seja, o inverso de $\subseteq$. A sentença em (19a) diz que o conjunto dos homens é um superconjunto do conjunto dos fumantes (isto é, contém todos os fumantes):

(20) Apenas os homens fumam.

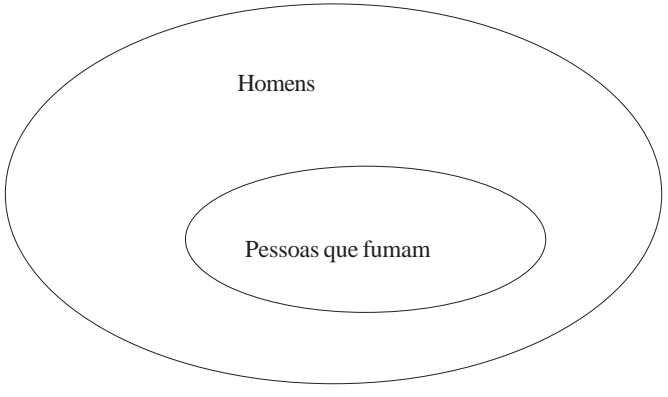


Podemos esquematizar isso da seguinte maneira:

(21) apenas os $\mathrm{N} \mathrm{V}=$ o conjunto dos $\mathrm{N}$ é um superconjunto do conjunto dos que $\mathrm{V}$

Portanto, apenas os exprime a relação inversa daquela expressa por todos (ou todos os) e todo. Mas vejamos se essa relação é conservativa. Para avaliarmos se é, devemos comparar (19a) com (19b), como fizemos com os outros determinantes. Essa última sentença parece dizer que existem homens que fumam que não são homens. Ou seja, o conjunto dos homens é um superconjunto do conjunto dos homens que fumam. Mas isso é banalmente verdadeiro. Como poderia não ser assim? Para tornar (19b) falsa, precisaríamos encontrar um homem que fuma, mas que não é homem. Em sentido literal, isso é impossível. Para (19a), por outro lado, é fácil imaginar situações que a tornam falsa. É evidente, portanto, que (19a) e (19b) não dizem a mesma coisa; apenas os não passa no teste da conservatividade. Essa expressão não exprime uma relação conservativa.

Devemos então concluir que nem todos os determinantes sejam conservativos, da mesma maneira que nem todos os verbos transitivos exprimem relações simétricas? Antes de poder responder afirmativamente essa pergunta, precisamos assegurar-nos de que apenas seja efetivamente parte de um determinante como todos. Para que apenas os possa ser classificado como um membro da categoria Det, ele precisa comportar-se sintaticamente como todos os outros membros dessa categoria. Isto é, ele precisa ocorrer na posição em que os determinantes tipicamente ocorrem. Mas, não é preciso muito esforço para ver que, com efeito, a gama de posições que apenas pode ocupar é bem mais ampla do que a dos determinantes. Vejamos alguns casos paradigmáticos: Em primeiro lugar, apenas pode ocorrer na posição típica dos advérbios:

$$
\begin{aligned}
& \text { a. Léo apenas veio. } \\
& \text { b. Léo sempre veio. }
\end{aligned}
$$

Podemos ver aqui que apenas ocupa a mesma posição que o advérbio sempre. Portanto, apenas se comporta, pelo menos em parte, como um advérbio. Por outro lado, apenas pode modificar ainda sintagmas preposicionados, coisa que os determinantes não podem fazer:
a. Apenas na Itália se come bem.
b. *Todo na Itália se come bem. 
Uma outra diferença clara é que apenas pode ocorrer com pronomes pessoais ou demonstrativos, enquanto que os determinantes não:

(24) a. Apenas ele pode fazê-lo.

b. Apenas isto conta.

c. *Um ele pode fazê-lo.

d. *Todo isto conta.

Existem, como acabamos de ver, diferenças macroscópicas na distribuição sintática que distinguem apenas os das expressões que são efetivamente determinantes. Esses fatos sugerem que apenas é um elemento adverbial que goza de uma certa liberdade de posicionamento na sentença. Isso é confirmado ainda pelo fato de que apenas apresenta a variante somente (com as mesmas propriedades sintáticas e semânticas) que ainda manifesta na sua roupagem morfológica (representada pelo sufixo -mente) o seu caráter adverbial. Portanto, aquilo que nos parecia, à primeira vista, um determinante não conservativo, num exame mais atento, se revelou não ser um determinante, mas sim um elemento adverbial.

E essa generalização vale não só para o português, mas também para todas as línguas naturais conhecidas. Até agora, em nenhuma língua na qual a categoria Det possa ser identificada, encontrou-se um determinante que exprima uma propriedade não conservativa. Isso nos leva à formulação do seguinte universal lingüístico:

Universal da conservatividade:

Se uma língua apresenta a categoria Det, todos os seus membros exprimem relações conservativas.

\section{Conclusão}

A conservatividade é uma propriedade abstrata das relações entre conjuntos e os determinantes só exprimem relações que apresentam essa propriedade. Há um número infinito de relações não-conservativas. Algumas delas são bastante naturais, a ponto de haver expressões que a denotem. Nós a exemplificamos com a relação de identidade, mas poderíamos ter apresentado 
muitos outros exemplos. Só que elas acabam sistematicamente pertencendo a outras categorias sintáticas. Para falsificar o universal em (25), basta encontrar alguma expressão com o significado análogo ao de 'ser igual a', numa língua qualquer, que se comporte sintaticamente como um determinante.

Não há nenhuma razão lógica que impeça isso. A existência de uma língua com um determinante que exprimisse a relação 'ser igual a' é perfeitamente concebível. Este determinante seria completamente coerente e comunicativamente útil. Mas isso não ocorre. As línguas exprimem relações como 'ser igual a' através de expressões de outras categorias sintáticas. A categoria Det é surpreendentemente especializada.

Até agora, não se sabe porque as línguas são desse jeito, já que não existe nenhuma exigência comunicativa que as levasse nessa direção. Por enquanto, podemos apenas limitar-nos a observar que, com efeito, as coisas parecem ser exatamente assim. Afinal, acabamos de descobrir algo de novo sobre como as línguas são feitas.

Palavras-chave: Determinante, interpretação semântica, conservatividade.

Key-words: Determiner, semantic interpretation, conservativity.

\section{REFERÊNCIAS}

CHIERCHIA, G. Semantica. In: Le struture del linguaggio. Bologna: II Mulino, 1997. 